\title{
Tandem Mass Spectrometry for the Direct Assay of Lysosomal Enzymes in Dried Blood Spots: Application to Screening Newborns for Mucopolysaccharidosis II (Hunter Syndrome)
}

\author{
Brian J. Wolfe ${ }^{\dagger}$, Sophie Blanchard ${ }^{\dagger}$, Martin Sadilek ${ }^{\dagger}$, C. Ronald Scott ${ }^{\ddagger}$, Frantisek \\ Turecek ${ }^{\dagger,}$, and Michael H. Gelb ${ }^{\dagger},{ }^{,}{ }^{,}$ \\ tDepartment of Chemistry, Bagley Hall, University of Washington, Box 351700, Seattle, \\ Washington 98195-1700, United States \\ FDepartment of Pediatrics, Division of Genetics and Development, RR 310 Health Science \\ Building, University of Washington, Box 356320, Seattle, Washington 98195-6320, United States \\ §Department of Biochemistry, University of Washington, Box 357350, Seattle, WA 98195-7350, \\ United States
}

\section{Abstract}

We have developed a tandem mass spectrometry based assay of iduronate-2-sulfatase (IdS) activity for the neonatal detection of mucopolysaccharidosis II (MPS-II, Hunter Syndrome). The assay uses a newly designed synthetic substrate (IdS-S) consisting of a-L-iduronate-2-sulfate, which is glycosidically conjugated to a coumarin and a linker containing a tert-butyloxycarbamido group. A short synthesis of the substrate has been developed that has the potential of being scaled to multigram quantities. Sulfate hydrolysis of IdS-S by IdS found within a $3 \mathrm{~mm}$ dried blood spot specifically produces a nonsulfated product (IdS-P) which is detected by electrospray tandem mass spectrometry and quantified using a deuterium-labeled internal standard, both carried out in positive ion mode. Analysis of DBS from 75 random human newborns showed IdS activities in the range of 4.8-16.2 (mean 9.1) $\mu \mathrm{mol} /(\mathrm{h} \mathrm{L}$ of blood), which were clearly distinguished from the activities measured for 14 MPS-II patients at $0.17-0.52$ (mean 0.29) $\mu \mathrm{mol} /(\mathrm{h} \mathrm{L}$ of blood). The assay shows low blank activity, $0.15 \pm 0.03 \mu \mathrm{mol} /(\mathrm{h} \mathrm{L}$ of blood). The within-assay coefficient of variation $(\mathrm{CV})$ was $3.1 \%$ while the interassay $\mathrm{CV}$ was $15 \%$.

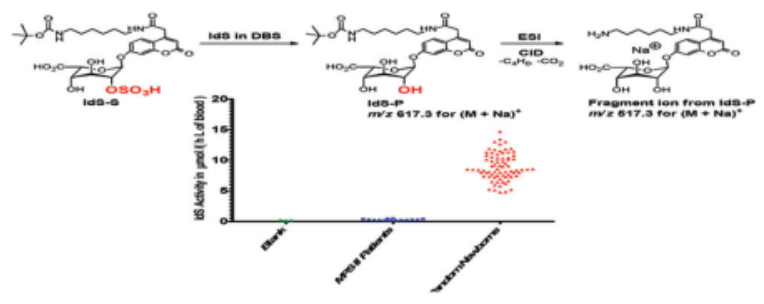

Mucopolysaccharidosis type II (Hunter syndrome; MPS-II) is a lysosomal storage disease that leads to the accumulation of glycosaminoglycans (GAGs) in nearly all tissues and

\section{(C) 2010 American Chemical Society}

"Corresponding Author: F.T.: address, Department of Chemistry, University of Washington, Campus Box 351700, Seattle Washington 98195; fax, 206-685-8665; turecek@ chem.washington.edu. M.H.G.: address, Departments of Chemistry and Biochemistry, University of Washington, Campus Box 351700, Seattle, Washington 98195; fax, 206-685-8665; gelb@chem.washington.edu.

Supporting Information. Additional information as noted in text. This material is available free of charge via the Internet at http://pubs.acs.org. 
organs. MPS-II is caused by a deficiency of iduronate-2-sulfatase (IdS, EC.3.1.6.13), an enzyme encoded by a gene located on the X-chromosome (Xq28), ${ }^{1}$ and, therefore, affects mainly males. Most affected individuals have point mutations or small deletions or insertions affecting the encoding gene; over 80 mutations have been described so far. ${ }^{1}$ It has been recognized that correlating the genotype and phenotype of MPS-II patients is not straightforward. Hence, detection of MPS-II on the basis of IdS activity appears to be advantageous. IdS catalyzes a step in the catabolic degradation of the GAGs dermatan and heparan sulfate (Scheme 1). Deficiency of IdS activity leads to the development of short stature in mildly affected individuals whereas severe cases present dysostosis multiplex, mental retardation, and death before 15 years. Enzyme replacement therapy of IdS has recently been introduced in an attempt to improve the clinical features of the condition. ${ }^{2}$ However, early detection of MPS-II is based on subtle clinical findings followed by appropriate enzyme assays; thus, the confirmation of diagnosis is often postponed, and potentially effective therapies are delayed. Efficient methods based on detection of enzyme activity are needed for early diagnosis in newborns.

Electrospray ionization tandem mass spectrometry (ESI-MSMS) has been used in newborn screening programs to quantify the level of metabolites associated with treatable diseases. ${ }^{3,4}$ We have developed ESI-MSMS assays for several mucopolysaccharidoses, ${ }^{5-8}$ including MPS-II, ${ }^{9}$ that used dried blood spots (DBS) from newborn screening laboratories as the biological sample. These assays use synthetic substrates that closely mimic the carbohydrate structure moieties in natural GAGs. At the same time, the enzymatic products and internal standards have been designed to have mutually exclusive molecular masses. Thus, enzyme activities in DBS from newborns can be monitored by MSMS in a multiplex fashion where products and internal standards from several enzyme assays can be combined and analyzed in a single injection.

The previously developed MPS-II assay used a substrate obtained in a few synthetic steps that included degradation of commercially available heparin with nitrous acid. ${ }^{9}$ Although this assay worked well, scale-up of substrate synthesis has proven to be problematic because of difficulties with variable heparin quality, handling large volumes of nitrous acid for heparin degradation, and removing impurities from the substrate. Hence, an improved procedure was needed to provide substrates and internal standards for large-scale assays such as those carried out by newborn screening laboratories. We report here the development of a new and improved ESI-MSMS assay that directly measures the reaction velocity of IdS in rehydrated dried blood spots (DBS) and is suitable for being adapted for the newborn screening of MPS-II. The new assay makes use of a modified substrate that can be prepared by total synthesis on a scale suitable for worldwide newborn screening, e.g., 10 $\mathrm{g}$ of substrate would be sufficient for about 600000 assays.

\section{EXPERIMENTAL SECTION}

\section{Materials}

All experiments were conducted in compliance with Institutional Review Board guidelines. All MPS-II affected patients had been diagnosed previously with established clinical and biochemical procedures. DBS were kept at ambient temperature during shipment ( $<10$ days) and then stored at $-20{ }^{\circ} \mathrm{C}$ in zip-lock plastic bags (one bag sealed inside a second bag). Ziplock bags were kept in a sealed plastic box containing desiccant (anhydrous $\mathrm{CaSO}_{4}$ granules). The synthesis of the IdS substrate (IdS-S) and the internal standard (IdS-IS) used previously established procedures ${ }^{5,10}$ as outlined in Scheme 2 and described in the Supporting Information. IdS-S, IdS-IS, and the deuterium-labeled linker were synthesized using readily available, inexpensive materials. The position of the $2^{\prime}$-sulfate group in Id-IS was confirmed by ${ }^{1} \mathrm{H}$ NMR on the basis of the characteristic chemical shift of the $\mathrm{C}-2^{\prime}$ 
proton which appears as a broad triplet at $\delta 4.493 \mathrm{ppm}$ in Id-IS and at $\delta 4.531 \mathrm{ppm}$ in the methyl ester precursor. That sulfation occurred selectively (>95\%) at $\mathrm{O}-2^{\prime}$ was established previously by $2 \mathrm{D}-\mathrm{NMR}$ analysis. ${ }^{10}$ The enzymatic product, IdS-P, is chemically identical with IdS-IS except that it contains a $t$-Boc group containing light ${ }^{1} \mathrm{H}$ isotopes.

\section{Standard Assay Procedure}

A $3 \mathrm{~mm}$ punch of a dried blood spot was placed in a $0.5 \mathrm{~mL}$ polypropylene tube (Eppendorf) containing $20 \mu \mathrm{L}$ of substrate solution consisting of $100 \mathrm{mM}$ sodium acetate, $\mathrm{pH} 5.5,25$ $\mathrm{mM}$ lead(II)acetate, $1.25 \mathrm{mM}$ substrate (IdS-S), and $1.2 \mathrm{nmol}$ internal standard (IdS-IS), which had previously been stored at $-20^{\circ} \mathrm{C}$. The solution was vortexed briefly then centrifuged to ensure the liquid had settled to the bottom of the tube. The capped tube was then incubated at $37^{\circ} \mathrm{C}$ for $16 \mathrm{~h}$ in a thermostatted air shaker. Then, $100 \mu \mathrm{L}$ of $44 \mathrm{mM}$ citric acid buffer was added to the solution, which adjusted the $\mathrm{pH}$ of the solution from 5.5 to 3.0, effectively protonating the carboxylic acids of both Id-P and Id-IS and making them more readily extractable. The citrate also precipitated much of the lead(II). Citric acid was chosen as the $\mathrm{pH}$-adjusting buffer because it effectively buffers at a $\mathrm{pH} \approx 3$, making it less likely that the sulfate bound to the substrate would be hydrolyzed non-enzymatically. Ethyl acetate $(400 \mu \mathrm{L})$ was then added, and the solution was vortexed for $10 \mathrm{~s}$ and then briefly centrifuged to separate the organic and aqueous layers, as well as to remove any precipitated solid or leftover blood spot from the organic layer. The top $300 \mu \mathrm{L}$ of ethyl acetate containing Id-P and Id-IS was then transferred to a separate Eppendorf tube. The solvent was removed by nitrogen stream, and the sample was reconstituted in $50 \mu \mathrm{L}$ of $80 / 20$ acetonitrile/water $+0.2 \%$ formic acid for mass spectrometry analysis. A blank assay was performed as above but using a blank paper punch instead of a DBS.

\section{Mass Spectrometry}

ESI-MS/MS was performed on a Waters Quattro Micro tandem quadrupole instrument using positive mode selected reaction monitoring (SRM) and sample flow injection at $0.1 \mathrm{~mL} / \mathrm{min}$. Using manual injection, a $10 \mu \mathrm{L}$ aliquot of the $50 \mu \mathrm{L}$ sample volume was injected for each analysis The mass transitions used for SRM analysis employed sodiated ions, e.g., $\mathrm{m} / z 617.3$ $\rightarrow \mathrm{m} / z 517.3$ and $\mathrm{m} / z 626.3 \rightarrow \mathrm{m} / z 518.3$ for IdS-P and IdS-IS, respectively. The product concentration was then determined from the SRM ion intensity ratio of the product $\left(I_{\mathrm{P}}\right)$ to internal standard $\left(I_{\mathrm{IS}}\right)$, the known internal standard concentration $\left(c_{\mathrm{IS}}\right)$, and the IdS-P/IdS-IS response ratio $(R)$. The enzyme activity was calculated as $\mu \mathrm{mol} /(\mathrm{h} \mathrm{L}$ of blood) from the amount of Id-P formed, the incubation time, and the blood volume in the DBS punch (3.2 $\mu \mathrm{L})$. The latter was estimated from the typical volume of blood in a DBS $(10 \mu \mathrm{L})$ and the punch/DBS area ratio. Other mass spectrometry settings were as follows: capillary voltage, $4000 \mathrm{~V}$; cone, $55 \mathrm{~V}$; extractor, $1 \mathrm{~V}$; RF lens, $0 \mathrm{~V}$; source temperature, $80^{\circ} \mathrm{C}$; desolvation temperature, $350{ }^{\circ} \mathrm{C}$; cone gas flow, $50 \mathrm{~L} / \mathrm{h}$; desolvation gas flow, $650 \mathrm{~L} / \mathrm{h}$; LM 1 resolution, 15; HM resolution, 15; ion energy 1, $0.2 \mathrm{eV}$; entrance, $15 \mathrm{~V}$; collision, $30 \mathrm{eV}$; exit, $15 \mathrm{~V}$; LM 2 resolution, 15; HM 2 resolution, 15; ion energy 2, $2.0 \mathrm{eV}$; multiplier, $650 \mathrm{~V}$; gas cell pirani pressure, $2.23 \times 10^{-3} \mathrm{mbar}$, dwell time $100 \mathrm{~ms}$ with $20 \mathrm{~ms}$ delay.

\section{RESULTS AND DISCUSSION}

The substrate consists of an umbelliferyl-a-L-iduronide sulfated at the O-2 position. The umbelliferyl group bears a hydrophobic linker with a terminal $t$-butyloxycarbamido ( $t$-Boc) group. IdS-IS is chemically identical with the enzymatic product from which it is distinguished by containing a $t$-Boc group with nine deuterium atoms (Scheme 3). Upon collision-induced dissociation, the fragmentation of the product and internal standard derived $(\mathrm{M}+\mathrm{Na})^{+}$ions occurs mainly by loss of $100 \mathrm{Da}$ for the product or $108 \mathrm{Da}$ for the internal standard due to a combined loss of isobutene and $\mathrm{CO}_{2}$ from the $t$-Boc group. ${ }^{11}$ This 
abundant dissociation pathway improves assay sensitivity by steering most of the product ion current into a single reaction channel. The IdS-S, IdS-P, and IdS-IS were also designed so that any obvious fragmentation pathways would not result in ions which overlapped with those used in our previously develop assays. This is very important because if compounds from different assays overlapped at critical masses the assays could not be multiplexed.

The combined elimination of isobutene and $\mathrm{CO}_{2}$ shown in Scheme 3 can be characterized as a charge-remote fragmentation ${ }^{12}$ analogous to ester or carbamate thermolysis, ${ }^{13}$ but presumably proceeding in a single step, as suggested by the absence of an intermediate due to elimination of isobutene. Density functional theory modeling of IdS-P and the $\mathrm{m} / z 617$ ion indicated that the sodium ion was attached to the sugar moiety and was remote from the dissociating carbamate group. The fully optimized structures of the reactants and the suggested dissociation mechanism are given as Scheme S3 (Supporting Information).

The effect of the deuterium label on the extractability of IdS-P relative to that of IdS-IS was examined and found to be only minor. Figure S1 (Supporting Information) shows that IdS-P was extracted at $94 \%$ of IdS-IS. The response ratio $(R)$ of IdS-P and IdS-IS in selected reaction monitoring was found to be 1.029 (Figure S2, Supporting Information). The relative response to IdS-P and IdS-IS showed good linearity $\left(r^{2}=0.997\right)$ over a $0-120 \mu \mathrm{M}$ range of concentrations corresponding to $0-2.4 \mathrm{nmol}$ of the product. This exceeds the typical range of IdS-P formed by assays in DBS by more than 5-fold, ensuring accurate product concentration measurements even at the high end of enzyme activities.

The $\mathrm{pH}$ dependence of the IdS activity was studied, and an optimum was found at $\mathrm{pH} 5.5$ in $100 \mathrm{mM}$ acetate buffer (Figure S3, Supporting Information). Sulfatases are inhibited by inorganic sulfate and phosphate, ${ }^{14}$ which have to be sequestered by precipitating as insoluble lead salts. ${ }^{6,7}$ In the absence of lead salts, IdS showed no activity in DBS (Figure S4, Supporting Information). Addition of lead(II)acetate restored IdS activity which reached an optimum at $25 \mathrm{mM} \mathrm{Pb}(\mathrm{OAc})_{2}$. This concentration of $\mathrm{Pb}(\mathrm{OAc})_{2}$ was used in IdS assays in DBS, because it is close to optimum lead salt concentrations in assays of other lysosomal sulfatases for the detection of MPS-IV ${ }^{6}$ and MPS-VI, ${ }^{7}$ to allow for their multiplexing. A 16 $\mathrm{h}$ assay incubation time was selected because it formed sufficient amounts of IdS-P to be detected by ESI-MS/MS and also was compatible with the work regime of a newborn screening lab. The IdS enzyme kinetics was studied to ascertain regular behavior toward IdS-S. The activity was found to increase in an approximately linear fashion over a $30 \mathrm{~h}$ incubation period (Figure S5, Supporting Information). This indicated that the enzyme kinetics was in the initial pseudolinear stage. The Michaelis-Menten parameters were also studied for IdS-S, and the $K_{\mathrm{M}}$ was established as $\sim 0.5 \mathrm{mM}$ with a $V_{\max } \approx 23 \mu \mathrm{mol} /(\mathrm{h} \mathrm{L}$ of blood) (Figure S6, Supporting Information). Therefore, a substrate concentration of 1.25 $\mathrm{mM}$ was used to saturate the enzyme in an effort to minimize the effect of potential competitive inhibitors present in blood. Figure S7 (Supporting Information) shows that the amount of IdS-P formed increases when a larger volume of blood is analyzed.

After having established the enzyme kinetics and identified potential interferences, we analyzed the IdS activity in DBS from 75 unaffected newborns and 14 MPS-II patients. The unaffected newborns displayed an activity range of $4.8-16 \mu \mathrm{mol} /(\mathrm{h} \mathrm{L}$ blood), with a mean activity of $9.1 \mu \mathrm{mol} /(\mathrm{h} \mathrm{L}$ blood) (Figure 1). The IdS activities measured for the MPS-II patients were $0.17-0.52 \mu \mathrm{mol} /(\mathrm{h} \mathrm{L}$ blood), with a mean IdS activity of $0.29 \mu \mathrm{mol} /(\mathrm{h} \mathrm{L}$ blood) (Table 1). Blank assays were carried out that included all components except the DBS and gave activities in the range of $0.12-0.19 \mu \mathrm{mol} /(\mathrm{h} \mathrm{L}$ blood) which were comparable to or below the values for affected MPS-II patients. The mean value of the IdS activities from affected patients was very low compared to that from unaffected individuals, just outside the $99.8 \%$ confidence limits of the blank, $0.15 \pm 0.1 \mu \mathrm{mol} /(\mathrm{h} \mathrm{L}$ of blood) at 3 
standard deviations. Due to the large separation of the data from the normal and affected individuals, the reported IdS activities were not blank corrected.

Assay precision was calculated using DBS from a healthy control. The within-assay coefficient of variation $(\mathrm{CV})$ was $3.1 \%(n=4)$ which involved four injections of the sample from incubation of a single DBS punch. The interassay CV was $15 \%(n=10)$ which was based on separate assays from 10 different punches of DBS while avoiding the blood spot perimeter. The interassay CV mainly reflects the variations in the amount and distribution of blood in the DBS.

The DBS from the MPS-II patients were collected in 2004 which raised the question of whether the low IdS activity in these samples could be due to limited enzyme stability. To test that the lack of IdS activity was not just due to DBS storage, two DBS samples from unaffected newborns collected at the same time were also analyzed. The activities for the aged DBS from normal controls, 15 and $16 \mu \mathrm{mol} /(\mathrm{h} \mathrm{L}$ of blood) were well within the range measured for freshly prepared DBS, indicating that samples stored at $-20{ }^{\circ} \mathrm{C}$ retain enzyme activity for at least 5 years. We note that IdS can also be assayed fluorimetrically with 4methyl-umbelifferyl $a$-iduronate-2-sulfate in coupling with glycolysis by purified $a$ iduronidase. ${ }^{15}$ The coupling enzyme releases the fluorescent reporter only after desulfation by IdS. The new IdS-S substrate developed in the present study can potentially be used in a fluorimetric assay of IdS. However, the ESI-MSMS assay has several advantages over the fluorimetric one in that (1) no coupling enzyme is necessary, (2) ESI-MSMS displays very low blanks so that blank correction is unnecessary, and (3) several enzymes can be assayed using a single infusion into the mass spectrometer. The blank issue is important because fluorimetric assays require that a blank be run for each DBS because the amount of background fluorescence varies with each patient sample.

\section{CONCLUSIONS}

In conclusion, a tandem mass spectrometry method has been developed for the direct assay of iduronate-2-sulfatase using dried blood spots from newborns that may be suitable for large-scale screening of MPS-II. The assay makes use of reagents that can be readily prepared in quantities to support newborn screening on a national or global scale. A suitable assay response is obtained with the amount of blood present in $1 / 4$ of a $3 \mathrm{~mm}$ DBS. The IdS assay is designed such that it should be possible to analyze the product together with those from other lysosomal enzyme assays by ESI-MSMS. ${ }^{16-18}$ This provides a technology allowing one to add IdS to the set of lysosomal enzymes to be assayed using the tandem mass spectrometer as a single and multiplexable analytical platform to achieve simultaneous detection of several lysosomal storage disorders in newborn screening centers. ${ }^{19,20}$

\section{Supplementary Material}

Refer to Web version on PubMed Central for supplementary material.

\section{Acknowledgments}

Support of this research by the NIH-National Institute of Diabetes, Digestive and Kidney Diseases (Grant R01 DK067859) is gratefully acknowledged.

\section{References}

1. Froissart R, Da Silva IM, Marie I. Acta Paediatr Suppl. 2007; 96:71-77. [PubMed: 17391447] 
2. Muenzer J, Wraith JE, Beck M, Giugliani R, Harmatz P, Eng CM, Velodi A, Martin R, Ramaswani U, Gucsavas-Calikoglu M, Vijayaraghavan S, Wendt S, Puga A, Ulbrich B, Shinawi M, Cleary M, Piper D, Conway AM, Kimura A. Genet Med. 2006; 8:465-473. [PubMed: 16912578]

3. Garg U, Dasouki M. Clin Biochem. 2006; 39:315-332. [PubMed: 16563365]

4. Chace DH, Kalas TA, Naylor EW. Clin Chem. 2003; 49:1797-1817. [PubMed: 14578311]

5. Blanchard S, Sadilek M, Scott CR, Turecek F, Gelb MH. Clin Chem. 2008; 54:2067-2070. [PubMed: 19042989]

6. Khaliq T, Sadilek M, Scott CR, Tureček F, Gelb MH. Clin Chem. 2011 in press.

7. Duffey TA, Sadilek M, Scott CR, Tureček F, Gelb MH. Anal Chem. 2010; 83:9587-9591. [PubMed: 20961069]

8. Duffey TA, Bellamy G, Elliott S, Fox AC, Glass M, Tureček F, Gelb MH, Scott CR. Clin Chem. 2010; 56:1854-1861. [PubMed: 20940330]

9. Wang D, Wood T, Sadilek M, Scott CR, Turecek F, Gelb MH. Clin Chem. 2007; 53:137-140. [PubMed: 17082248]

10. Blanchard S, Turecek F, Gelb MH. Carbohydr Res. 2009; 344:1032-1033. [PubMed: 19356745]

11. Li Y, Scott CR, Chamoles NA, Ghavami A, Pinto BM, Turecek F, Gelb MH. Clin Chem. 2004; 50:1785-1796. [PubMed: 15292070]

12. Adams J. Mass Spectrom Rev. 1990; 9:141-186.

13. (a) Daly NJ, Ziolkowski F. J Chem Soc Chem Commun. 1972:911-912.(b) Brown, RFC. Pyrolytic Methods in Organic Chemistry. Vol. Chapter 4. Academic Press; New York: 1980. p. 89-90.

14. Hanson SR, Best MD, Wong CH. Angew Chem, Int Ed. 2004; 43:5736-5763.

15. Voznyi YV, Keulemans JL, van Diggelen OP. J Inherit Metab Dis. 2001; 24:675-680. [PubMed: 11768586]

16. Li Y, Brockman K, Turecek F, Scott CR, Gelb MH. Clin Chem. 2004; 50:638-640. [PubMed: 14981030]

17. Gelb MH, Tureček F, Scott CR, Chamoles NA. J Inherited Metab Dis. 2006; 29:397-404. [PubMed: 16763908]

18. Turecek, F.; Gelb, MH.; Scott, CR. Methods Molecular Biology. Secchi, S., editor. Totowa: Humana Press; 2005.

19. Orsini JJ, Morrissey MA, Slavin LN, Wojcik M, Biski C, Martin M, Keutzer J, Zhang XK, Chuang WL, Elbin C, Caggana M. Clin Biochem. 2009; 42:877-884. [PubMed: 19318021]

20. Dajnoki A, Muehl A, Fekete G, Keutzer J, Orsini JJ, DeJesus V, Zhang XK, Bodamer OA. Clin Chem. 2008; 54:1624-1629. [PubMed: 18703766] 


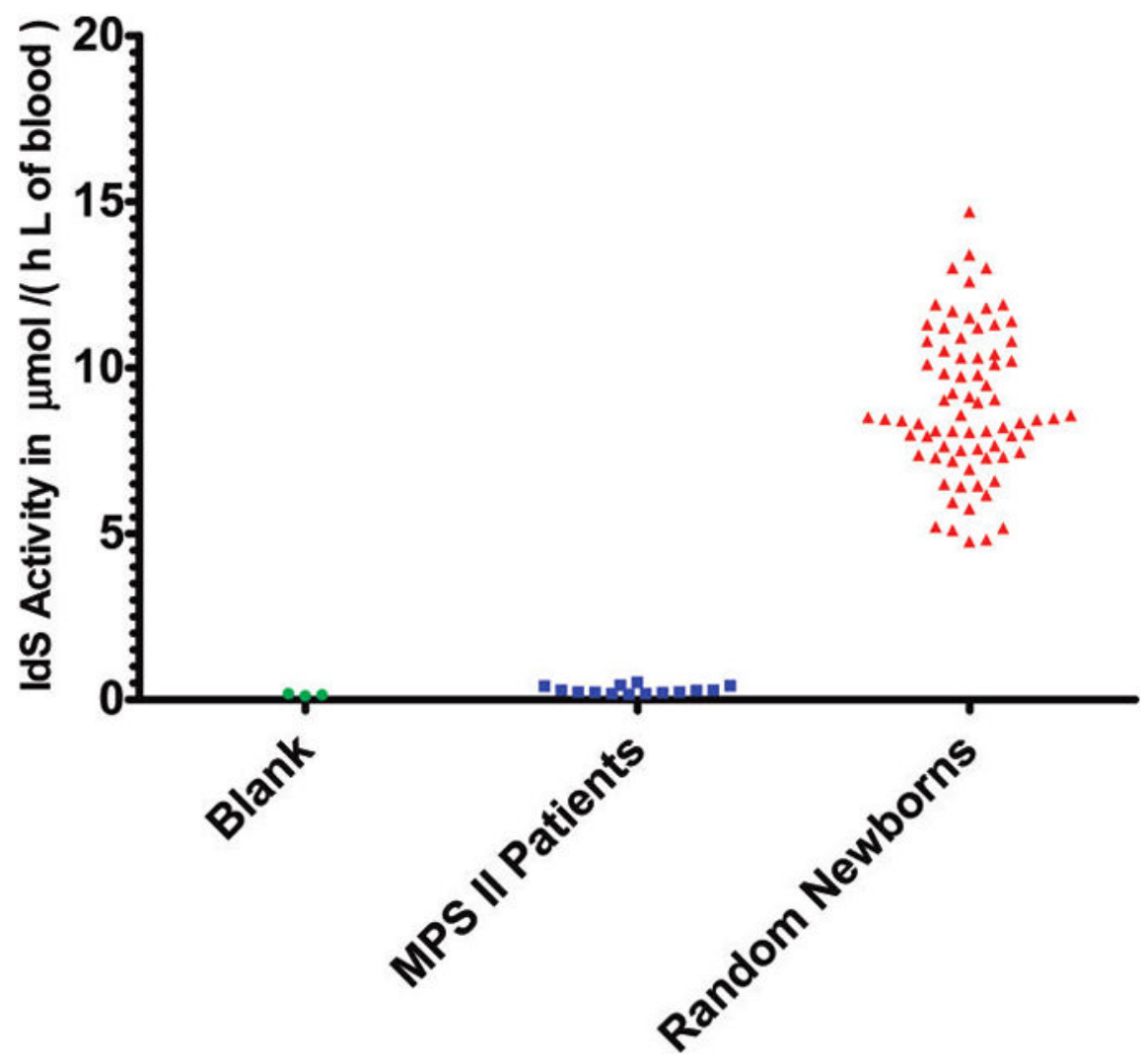

Figure 1.

Iduronate-2-sulfatase activities in DBS from 14 MPS II patients (blue points) and 75 random newborns (red points). The range of measured activities for the MPS II patients and random newborns was 0.17-0.52 (average 0.29) and 4.8-16 (average 9.1) $\mu \mathrm{mol} /(\mathrm{h} \mathrm{L}$ blood), respectively. 

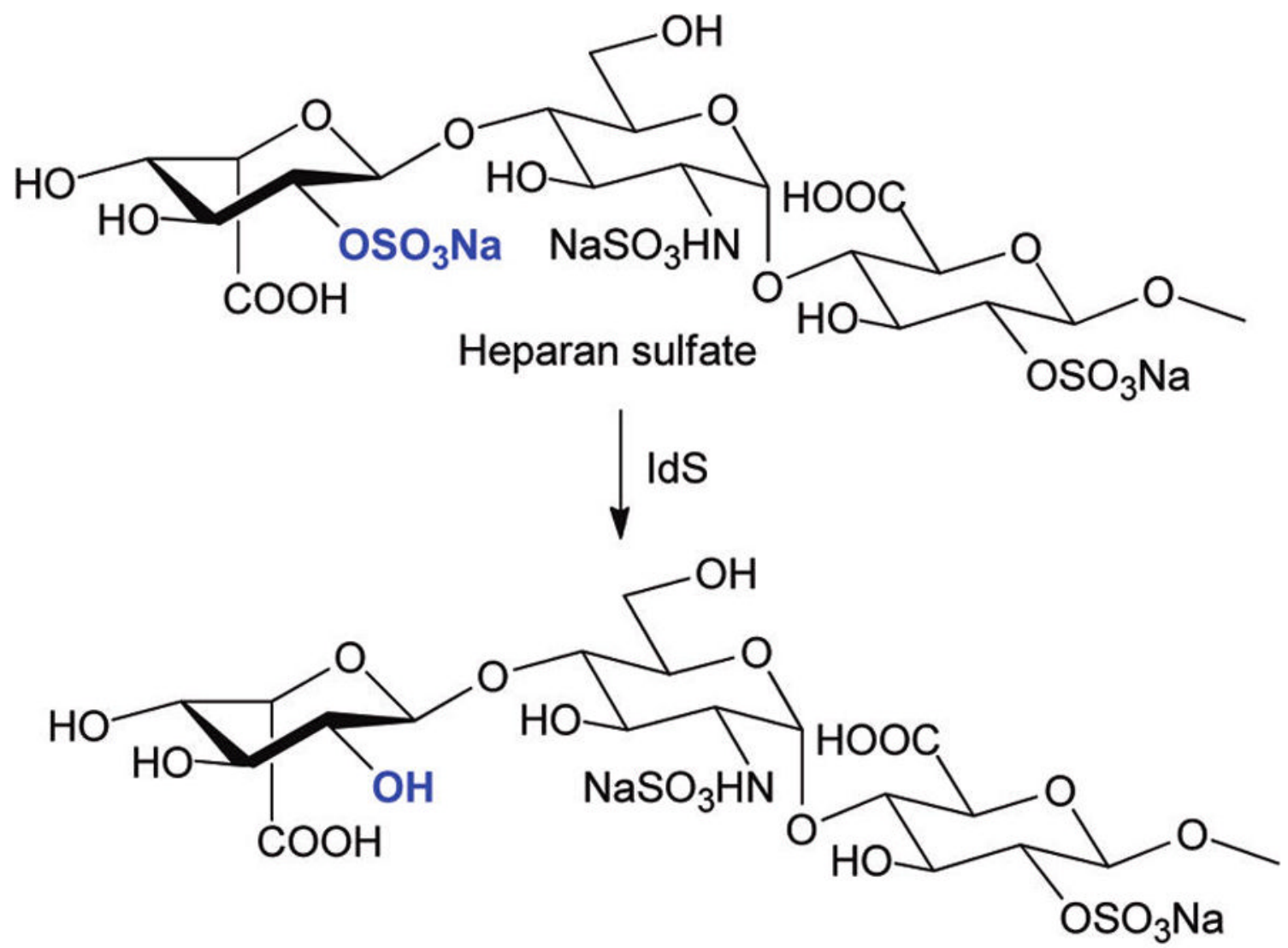

Scheme 1. 


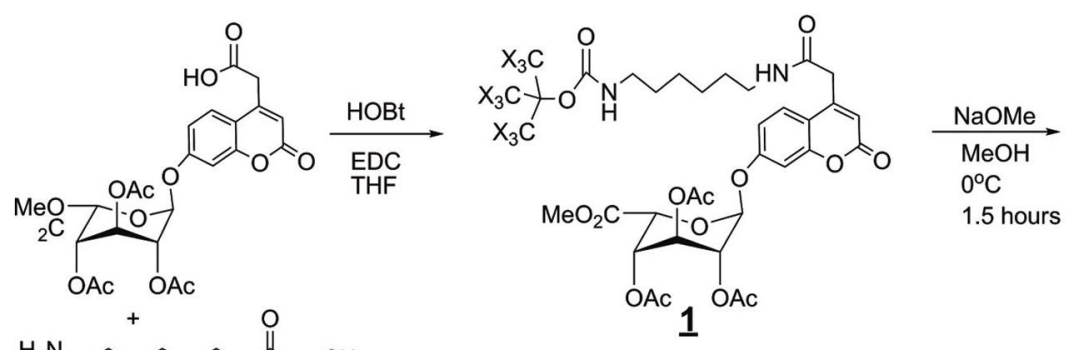<smiles>[X]=C([O-])OC(=O)NCCCCCCN</smiles>

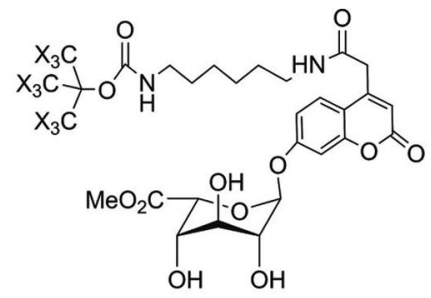<smiles>CCNCCCCCCNC(=O)OC(C)(C)C</smiles>

3

$\mathrm{NaOH}$

$\mathrm{Me}_{3} \mathrm{~N}^{*} \mathrm{SO}_{3}$

DMF

18 Hours

$\mathrm{H}_{2} \mathrm{O} / \mathrm{MeOH}$ 1:1<smiles>CC(C)(C)OC(=O)NCCCCCCNC(=O)Cc1cc(=O)oc2cc(OO)ccc12</smiles>

$\mathrm{H}_{3} \mathrm{C}$ )

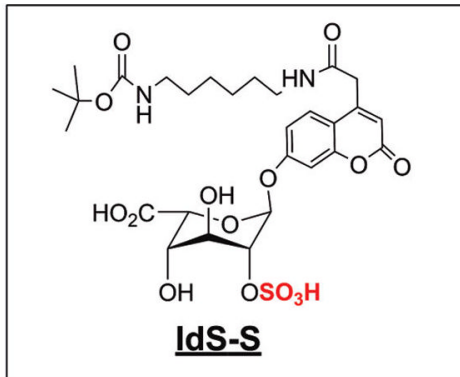

Scheme 2. 


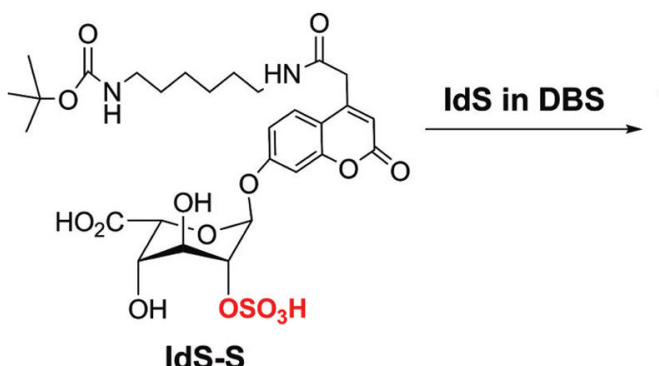

IdS-S

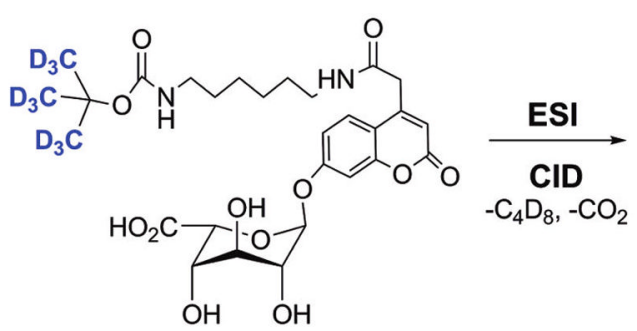

IdS-IS

$m / z 626.3$ for $(\mathrm{M}+\mathrm{Na})^{+}$<smiles>CC(C)(C)OC(=O)NCCCCCCCCCNC(=O)Cc1cc(=O)oc2cc(OC3O[C@H](C(=O)O)[C@@H](O)[C@H](C(=O)O)[C@H]3O)ccc12</smiles>

IdS-P

$\mathrm{m} / \mathrm{z} 617.3$ for $(\mathrm{M}+\mathrm{Na})^{+}$<smiles>CCC(=O)OC(=O)CC</smiles>

.

and

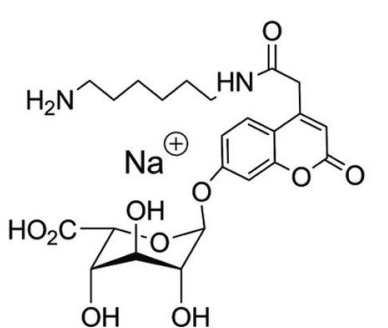

Fragment ion from IdS-P $\mathrm{m} / \mathbf{z} 517.3$ for $(\mathrm{M}+\mathrm{Na})^{+}$

Scheme 3. 


\section{Table 1}

Iduronate-2-sulfatase Activities in $\mu \mathrm{mol} /(\mathrm{h} \mathrm{L}$ of Blood)

\begin{tabular}{lll}
\hline blank & MPS II patients & random newborns \\
\hline$n=3$ & $n=14$ & $n=75$ \\
0.148 & 0.235 & $4.82,11.2,6.58,5.21,8.48$ \\
0.188 & 0.181 & $11.3,7.63,11.5,11.8,10.9$ \\
0.119 & 0.231 & $10.1,10.3,11.7,10.3,5.94$ \\
& 0.181 & $11.9,8.05,10.5,8.56,7.37$ \\
& 0.281 & $9.73,6.16,7.55,7.99,6.49$ \\
& 0.292 & $10.8,9.78,8.43,14.7,7.19$ \\
& 0.215 & $8.51,7.98,7.28,9.23,7.94$ \\
& 0.292 & $11.4,5.10,10.4,13.4,8.95$ \\
& 0.225 & $10.2,9.83,5.17,13.0,4.76$ \\
& 0.410 & $6.94,7.51,12.6,7.29,5.74$ \\
& 0.438 & $8.34,9.12,11.9,9.47,10.1$ \\
& 0.415 & $11.3,8.20,13.0,8.09,8.40$ \\
& 0.169 & $7.65,8.09,7.95,7.31,8.10$ \\
& 0.521 & $7.45,6.44,9.02,8.45,10.8$ \\
& & $6.41,11.2,9.04,8.57,8.32$ \\
\hline
\end{tabular}

